\title{
Ultra-structural cell distribution of the melanoma marker iodobenzamide: improved potentiality of SIMS imaging in life sciences
}

\author{
Jean-Luc Guerquin-Kern ${ }^{1}$, François Hillion ${ }^{2}$, Jean-Claude Madelmont ${ }^{3}$, \\ Pierre Labarre $^{3}$, Janine Papon ${ }^{3}$ and Alain Croisy* 1
}

\begin{abstract}
Address: ${ }^{1}$ INSERM U-350, laboratoire Raymond Latarjet, Bâtiment 112, Centre Universitaire, 91405 Orsay, France, ${ }^{2}$ CAMECA France, 103 Boulevard Saint Denis, BP 6, 92403 Courbevoie cedex, France and ' INSERM U-484, Centre de recherche INSERM, Rue Montalembert, BP 184, 63005 Clermont Ferrand cedex, France

Email: Jean-Luc Guerquin-Kern - jean-luc.guerquin-kern@curie.u-psud.fr; François Hillion - hillion@cameca.fr; JeanClaude Madelmont - madelmont@Inserm484.u-clermont1.fr; Pierre Labarre - labarre@Inserm484.u-clermont1.fr; Janine Papon - papon@Inserm484.u-clermont1.fr; Alain Croisy* - alain.croisy@curie.u-psud.fr

* Corresponding author
\end{abstract}

Published: 06 April 2004

BioMedical Engineering OnLine 2004, 3:10
Received: 21 November 2003

Accepted: 06 April 2004

This article is available from: http://www.biomedical-engineering-online.com/content/3/1/10

(C) 2004 Guerquin-Kern et al; licensee BioMed Central Ltd. This is an Open Access article: verbatim copying and redistribution of this article are permitted in all media for any purpose, provided this notice is preserved along with the article's original URL.

\begin{abstract}
Background: Analytical imaging by secondary ion mass spectrometry (SIMS) provides images representative of the distribution of a specific ion within a sample surface. For the last fifteen years, concerted collaborative research to design a new ion microprobe with high technical standards in both mass and lateral resolution as well as in sensitivity has led to the CAMECA NanoSims 50, recently introduced onto the market. This instrument has decisive capabilities, which allow biological applications of SIMS microscopy at a level previously inaccessible. Its potential is illustrated here by the demonstration of the specific affinity of a melanoma marker for melanin. This finding is of great importance for the diagnosis and/or treatment of malignant melanoma, a tumour whose worldwide incidence is continuously growing.
\end{abstract}

Methods: The characteristics of the instrument are briefly described and an example of application is given. This example deals with the intracellular localization of an iodo-benzamide used as a diagnostic tool for the scintigraphic detection of melanic cells (e.g. metastasis of malignant melanoma). BI6 melanoma cells were injected intravenously to $\mathrm{C}_{57} \mathrm{BL}_{6} / \mathrm{J}_{1} / \mathrm{co}$ mice. Multiple BI6 melanoma colonies developed in the lungs of treated animals within three weeks. lodobenzamide was injected intravenously in tumour bearing mice six hours before sacrifice. Small pieces of lung were prepared for SIMS analysis.

Results: Mouse lung B 16 melanoma colonies were observed with high lateral resolution. Cyanide ions gave "histological" images of the cell, representative of the distribution of $\mathrm{C}$ and $\mathrm{N}$ containing molecules (e.g. proteins, nucleic acids, melanin, etc.) while phosphorus ions are mainly produced by nucleic acids. lodine was detected only in melanosomes, confirming the specific affinity of the drug for melanin. No drug was found in normal lung tissue.

Conclusion: This study demonstrates the potential of SIMS microscopy, which allows the study of ultra structural distribution of a drug within a cell. On the basis of our observations, drug internalization via membrane sigma receptors can be excluded. 


\section{Background}

Progress in cellular imaging allows access not only to qualitative aspects of living structures but also to quantitative data. These data are of considerable interest, especially in pharmaco-toxicology, to understand the mechanisms by which drugs interact with physiological processes. Such analytical methods have, for a long time, been restricted to fluorescence measurements, either directly or after immuno-conjugation, thus severely limiting the development of such applications. In the last few decades, new techniques have appeared, including X-ray fluorescence, electron energy loss spectroscopy, and secondary ion mass spectroscopy (SIMS).

Initially introduced 40 years ago [1], SIMS imaging has found its main uses in microanalysis of mineral samples, e.g. in geology, metallurgy, and semiconductor sciences. Application of this "ion microscopy" to life sciences was attempted by Pierre Galle more than 30 years ago [2]. However, the complex nature of biological samples and the poor performance of the first instruments limited its use to various "histological" studies, mainly in nuclear medicine and radionuclide toxicology.

SIMS imaging is based on the sputtering of secondary particles under the impact of high-energy primary ions. Upon the impact of these primary ions, most chemical bonds are broken and atoms or polyatomic fragments are ejected from the most superficial atomic layers of the specimen (1-2 nm), either as neutral or charged particles (ions). Ions can be selected by a mass spectrometer on the basis of their mass to charge ratio $(\mathrm{m} / \mathrm{z})$, while maintaining the topological information of their origin intact thus leading to images representative of the spatial distribution of a specific ion within the sample surface. This imaging technique has been recently reviewed on the basis of past experiments using standard technology [3-5]. For the last fifteen years, concerted collaborative research to design a new ion microprobe with high technical standards in both mass and lateral resolutions as well as in sensitivity has led to the CAMECA NanoSims $50[6,7]$ recently introduced on the market (Cameca S.A., Courbevoie, France, http://www.cameca.fr). A highly simplified diagram of this new instrument is given in figure 1 . This machine has decisive capabilities, which can be used for biological applications of SIMS microscopy at a level previously inaccessible. The main characteristics of this new ion microscope are:

i) high lateral resolution ( $\leq 50 \mathrm{~nm}$ with caesium primary ions and $\leq 150 \mathrm{~nm}$ with oxygen primary ions),

ii) capability to measure up to 5 masses (ions) in parallel, coming from the same micro volume (ensuring perfect isotopic ratio from the same small volume or perfect image superimposition)

iii) very good transmission, e.g. high sensitivity, even at high mass resolution $(60 \%$ at $\mathrm{M} / \Delta \mathrm{M}=5000)$.

The main advantage of this technology is the ability to make direct observation of the distribution of any element (and all isotopes) occurring at the surface of a sample, without any specific labelling with a fluorescent or radioactive probe.

In the present paper, we describe an example of application of this new ion microprobe to a problem in cancer pharmacology, the targeting of melanin for the diagnosis and/or the treatment of malignant melanoma.

The worldwide incidence of malignant melanoma is continuously increasing [8,9] and it is now evident that diagnosis at an early stage is the most effective way to limit mortality. The most common tool to determine the extent of the disease is whole body scintigraphic exploration and, for this purpose, two classes of compounds are currently under investigation, ${ }^{18} \mathrm{~F}$-fluorodeoxyglugose ( $\left.{ }^{18} \mathrm{FdG}\right)$, a non-specific tumoral tracer [10], and ${ }^{125}$ I-iodobenzamides (125I-BZA), a series of specific imaging agents for melanoma [11-16]. These latter molecules can also be used as internal radio therapeutic agents after labelling with the $\beta$-emitter ${ }^{131}$ I. Whilst the affinity of these iodobenzamides for melanoma tissue has been the subject of numerous studies, their tissue and cell distribution as well as their uptake mechanism remain controversial. A recent SIMS microscopy study of tissues that were either neoplastic or from normal pigmented skin, of $\mathrm{C}_{57} \mathrm{Bl}_{6} / \mathrm{J}_{1}$ mice inocculated with malignant murine $\mathrm{B} 16$ melanocytes has shown the intracytoplasmic localization of the drug in both types of cell. However, lateral resolution of the instrument was too low to identify any characteristic intra-cellular structure such as melanosomes, and so the results were not fully conclusive [17]. The results presented here demonstrate unambiguously the specific affinity of the studied iodobenzamide for melanin pigments present within melanosomes.

\section{Methods}

B16 murine melanoma cells were cultivated in minimal essential medium (MEM) supplemented with 10\% foetal calf serum (FCS) and standard antibiotics. For transplantation, cells were trypsinized and washed with buffered saline (PBS) containing 5\% FCS. Then, cells were resuspended in PBS $\left(1.5 \times 10^{-6}\right.$ cells $\left./ \mathrm{mL}\right)$ and $0.2 \mathrm{~mL}$ of the suspension was injected intravenously to $\mathrm{C}_{57} \mathrm{BL}_{6} / \mathrm{J}_{1} /$ co mice (Iffa Credo, France). Multiple B16 melanoma colonies developed in the lungs within three weeks. All animal use 


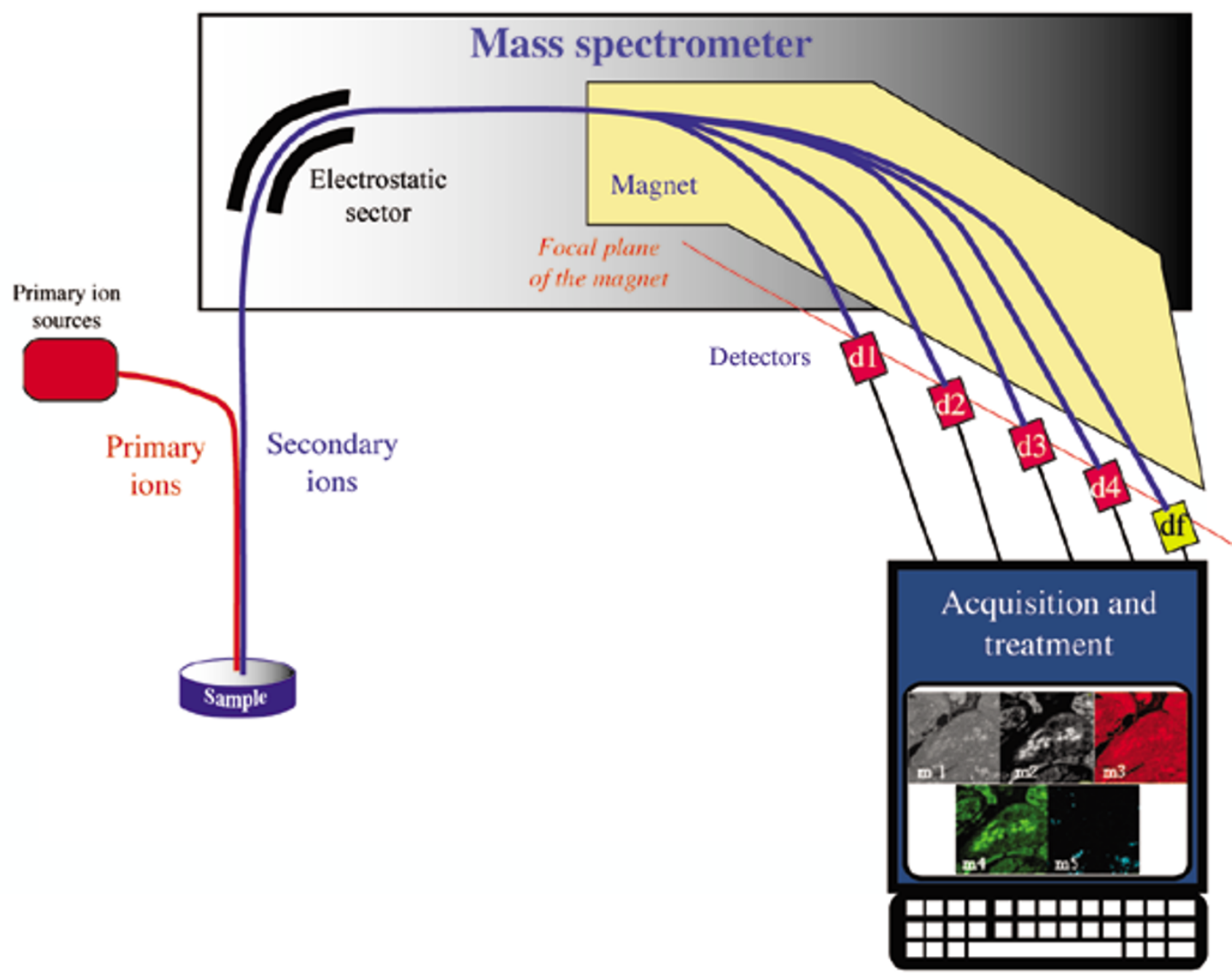

Figure I

Synopsis of the instrument. Highly simplified synopsis of the NanoSims $50^{\circledR}$ instrument showing the beams of primary (red) and secondary (blue) ions and the five detectors along the focal plane of the magnet.

and handling was carried out following Institutional guidelines for animal welfare.

$\mathrm{N}$-2-Diethylaminoethyl-4-iodobenzamide (127I-BZA) was injected intravenously in tumour bearing mice $(0.9 \mathrm{mg} /$ $0.2 \mathrm{~mL} / \mathrm{mouse} ; 2.6$ mole) 6 hours before sacrifice. Lungs were removed and small pieces of tissue were fixed by slam freezing. Samples were dehydrated by lyophilization at $-110^{\circ} \mathrm{C}$ before embedding in spurr ${ }^{\circledast}$ resin at low temperature. Serial sections of $0.4 \mu \mathrm{m}$ were deposited on stainless steel disks for SIMS analysis or on glass slides for light microscopy.
SIMS observations were carried out on a Nanosims $50^{6}$ micro beam analyzer (CAMECA, Courbevoie, France) using a $\mathrm{Cs}^{+}$primary source $(15 \mathrm{KeV})$. The probe was 80 $\mathrm{nm}$ in diameter, with an intensity of $1.5 \mathrm{pA}$. Distribution of negative ions: $\mathrm{CN}^{-}(\mathrm{m}=27), \mathrm{P}^{-}(\mathrm{m}=31)$, and $\mathrm{I}^{-}(\mathrm{m}=$ 127 ) was recorded as a matrix of $256 \times 256$ image points.

Mass resolution $(\mathrm{M} / \Delta \mathrm{M})$ was above 6000 and mass calibration was achieved using standard references. Lateral resolution was in the range $80-100 \mathrm{~nm}$.

\section{Results}

As shown on an optical image (Fig. 2), B16 colonies appear as clusters of large cells, which can be easily 


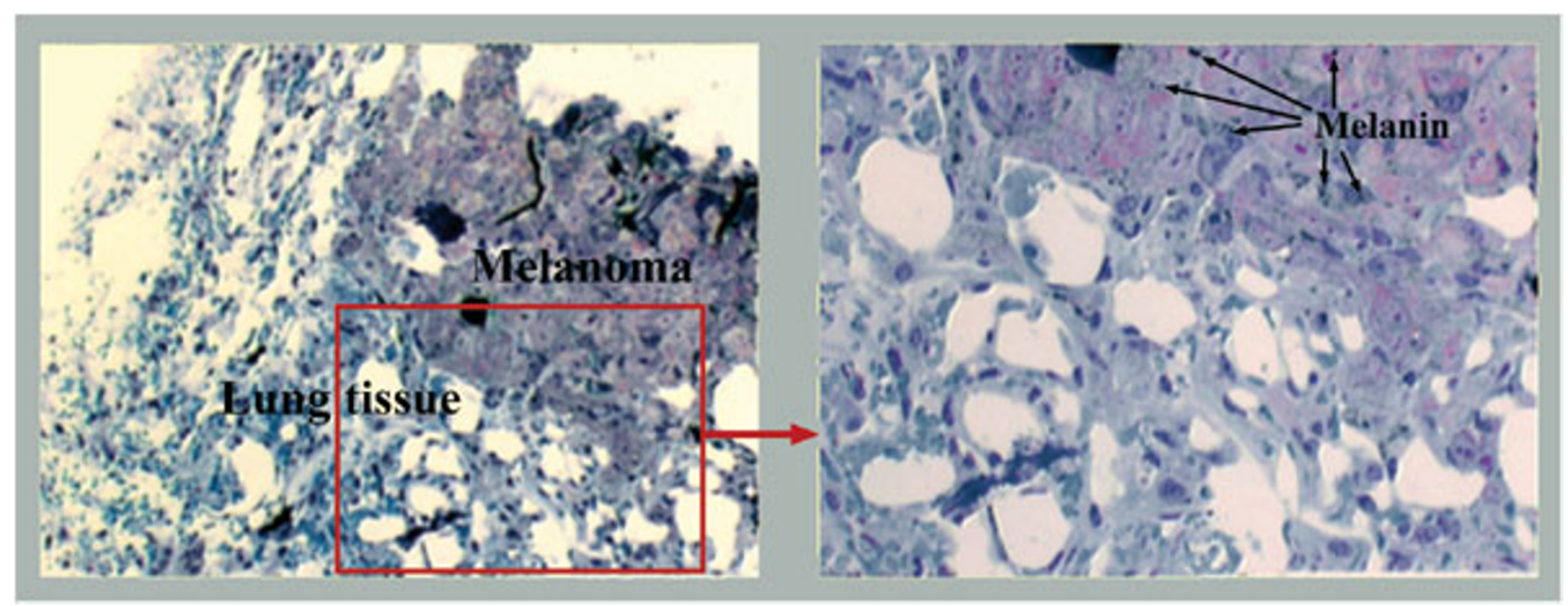

Figure 2

B I 6 melanoma colonies. Histological sections $(0.4 \mu \mathrm{m})$ of mouse lung bearing BI 6 melanoma colonies $(\times 200$, left and $\times 400$, right). Melanoma cells appear as large and dense structures with many dark grains of melanin.

differentiated from the surrounding lung tissue. Melanin grains can be seen as small black spots, which are characteristic of all pigmented melanoma cells. Sims images centred on one B16 colony are given in figures 3 and 4 , while figure 5 is representative of normal lung tissue.

$\mathrm{CN}^{-}$ions correspond to nitrogen distribution, mainly from proteins and melanin, while phosphorus ions are essentially concentrated in the nucleus and are mostly emitted by nucleic acids. However, as expected, phosphorus is also apparent everywhere in the cell, whilst iodide ions only arise from BZA or/and its metabolites.

$\mathrm{CN}^{-}$distribution gives an image very similar to that obtained using light microscopy. We can observe some small grains (150-250 $\mathrm{nm}$ in diameter) as well as a cluster of such grains (Figs. 3A and 3D) with a very high signal intensity. These hyper signal areas are totally free of phosphorus signal (Figs. 3B and 3E), as expected for melanin, which is a polymeric structure containing no phosphorus. A perfect correlation is found between these structures and the iodine signal (Figs. 3C and 3F), thus indicating a specific colocalization of the drug with melanin. The cluster, which can be considered as a melanosome, and most melanin grains, are intracytoplasmic and no iodine signal can be observed at the cytoplasmic membrane locus. Therefore, our results invalidate, at least for $\mathrm{N}$-2-diethylaminoethyl-4-iodobenzamide, the hypothesis of John and colleagues implicating a specific binding of benzamides to membrane sigma receptors $[18,19]$. The same observations are true for figure 4 , however, here the melanin grains are rare. Interestingly, in the $\mathrm{CN}^{-}$image (Fig. 4A), the central cell of the picture does not show any structured nucleus but rather a "patchwork" of high signal areas, which appear as very intense signals in the phosphorus image (Fig. 4B). This is consistent with a metaphasic cell in which the chromatin is already condensed into chromosomes. Normal lung tissue, shown in figure 5, did not elicit any significant iodine signal, thus indicating the high specificity of the drug for the melanin of pigmented cells.

\section{Conclusions}

Iodobenzamide has a high affinity for melanin and, when labelled with ${ }^{125} \mathrm{I}$, this molecule appears as a highly specific tool for the diagnosis of micro metastasis from pigmented malignant melanoma. Its use as an internal radionuclide therapeutic agent bearing the $\beta$-emitter ${ }^{131}$ I is currently under investigation. However, the therapeutic protocol should be established with great care, since BZA can also bind to normal pigmented cells, i.e. in the retina or in the skin, which can be destroyed as along with the targeted malignant cells.

This study demonstrates the high potential of SIMS microscopy, which now allows the study of ultra structural distribution of a drug within a cell. The high lateral resolution, as well as the high sensitivity, make possible the observation of organelles as small as melanosomes. This new technology merits further applications to the life sciences as a major advance to an "old". 


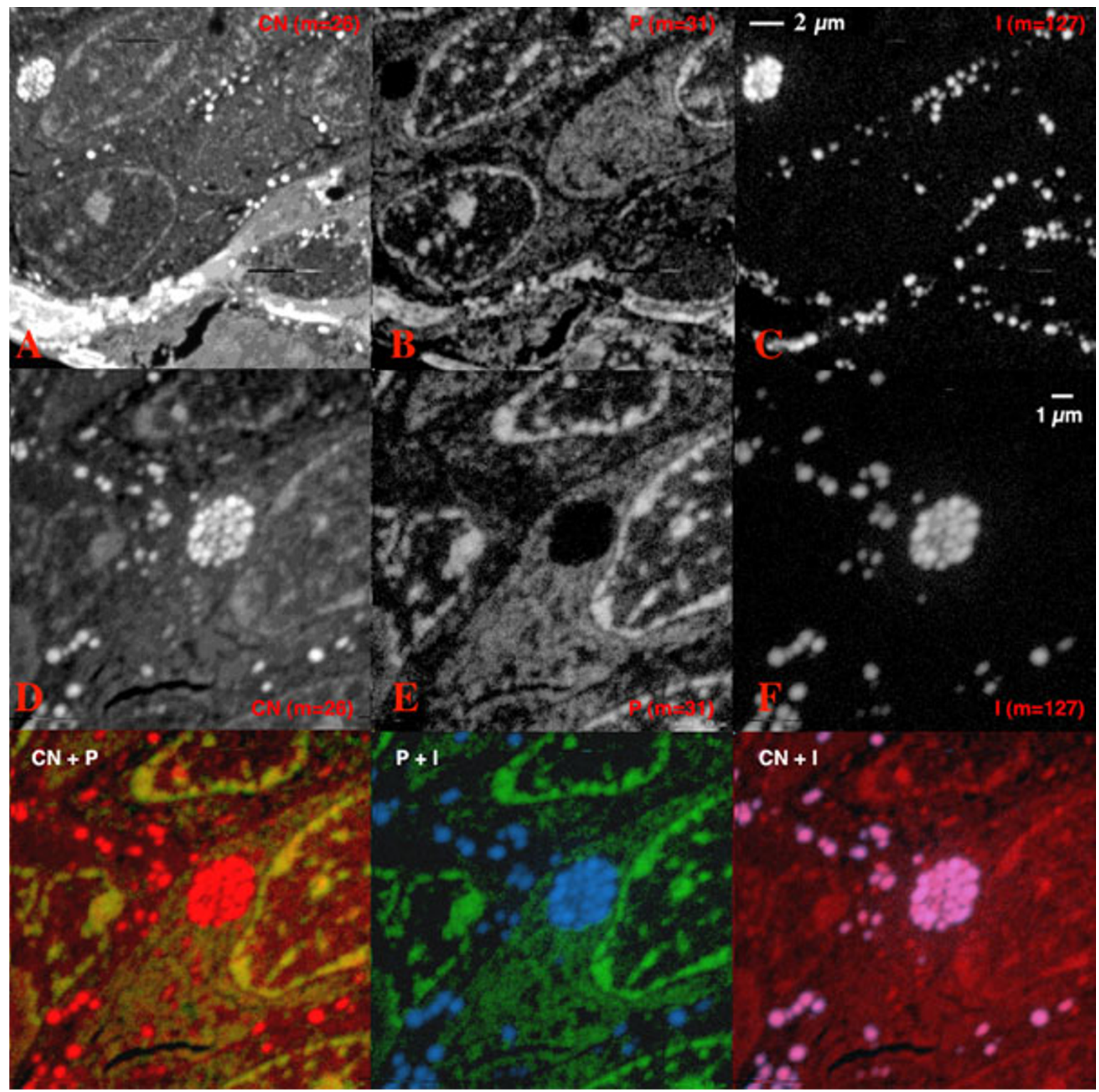

\section{Figure 3}

Secondary negative ion images of B 16 melanoma cells from a mouse lung colony. $A$ \& $D$ : $C N$ - ions $(m=26)-B$ \& E: $P$-ions $(m=3 I)-C \& F$ : $I$ - ions $(m=127)$. D-F are enlargements of the top left part of $A-C$. In the bottom row, the use of specific colours for each type of ion (red for $\mathrm{CN}$, green for $\mathrm{P}$ and blue for I) allows the superimposition of the various images leading to colour variations resulting from the co-localization of the observed ions. Thus, yellow coloration in $\mathrm{CN}+\mathrm{P}$ corresponds to the co-localisation of $\mathrm{CN}$ - and $\mathrm{P}$ - ions while a co-localization of the iodine with very intense spots of the $\mathrm{CN}$ image (purple coloration in $\mathrm{CN}+\mathrm{I}$ ) can be seen. This iodine signal corresponds to the melanin, which appears in red on the $\mathrm{CN}+\mathrm{P}$ image and in blue on the $\mathrm{P}+\mathrm{l}$ image, since melanin does not contain any phosphorus. The strongest signals in the phosphorus image are attributed to cell nucleus, namely to active chromatin and nucleoli. Observed fields A-C: $20 \mu \mathrm{m} \times 20 \mu \mathrm{m}, \mathrm{D}-\mathrm{F}$ and superimpositions: $10 \mu \mathrm{m} \times 10 \mu \mathrm{m}$. 


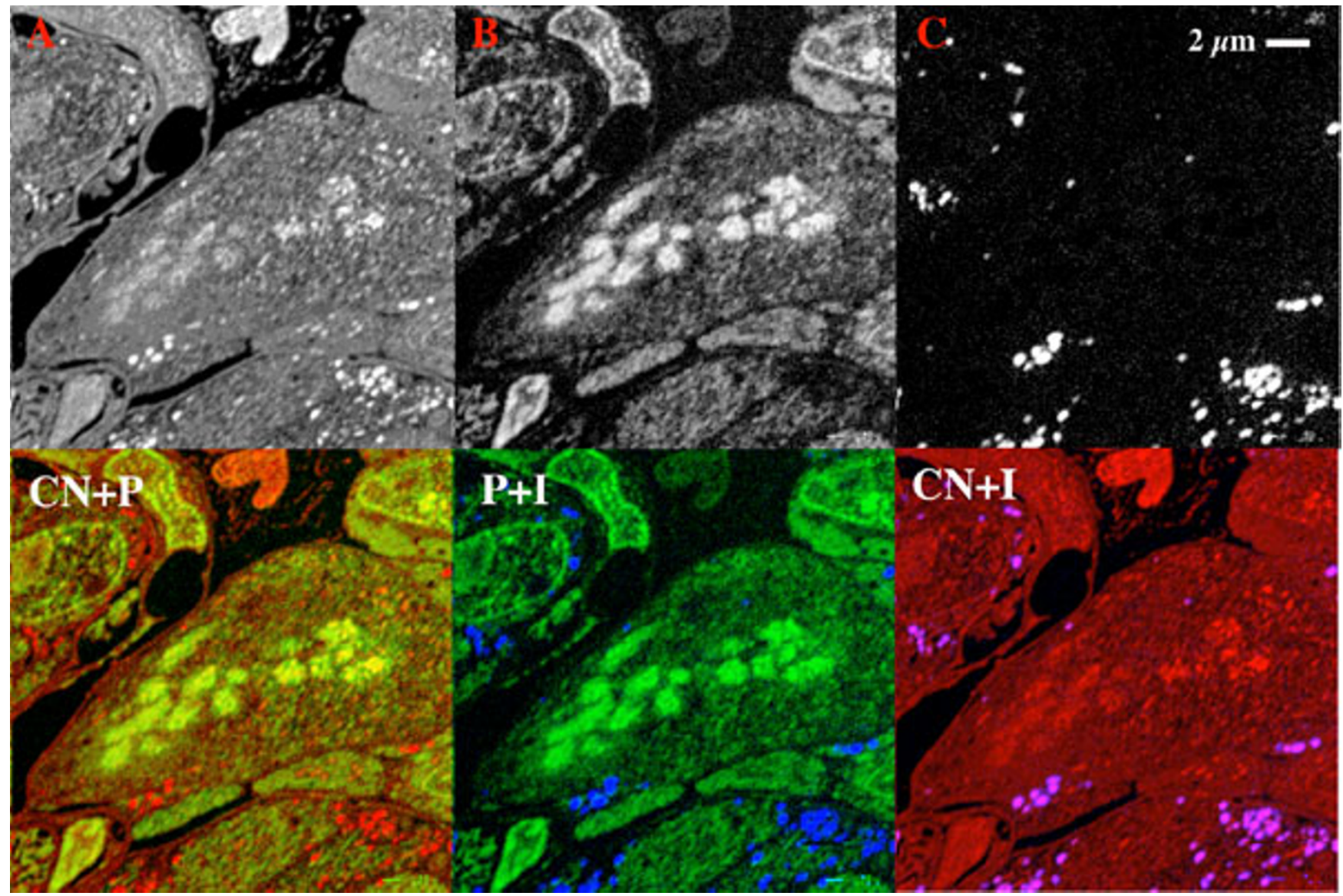

Figure 4

SIMS images of B I 6 melanoma cells from a mouse lung colony. $A$ : $C N^{-}$ions $(m=26) B$ : $P$-ions $(m=3 I)-C$ : $I-i o n s(m$ $=127$ ), field $20 \times 20 \mu \mathrm{m}$. As shown in figure 3, false colors allow the superimposition of the various ions. lodine is strictly colocalized with melanin, which is essentially intracytoplasmic. The central cell is metaphasic and chromosomes can be seen in the pictures.
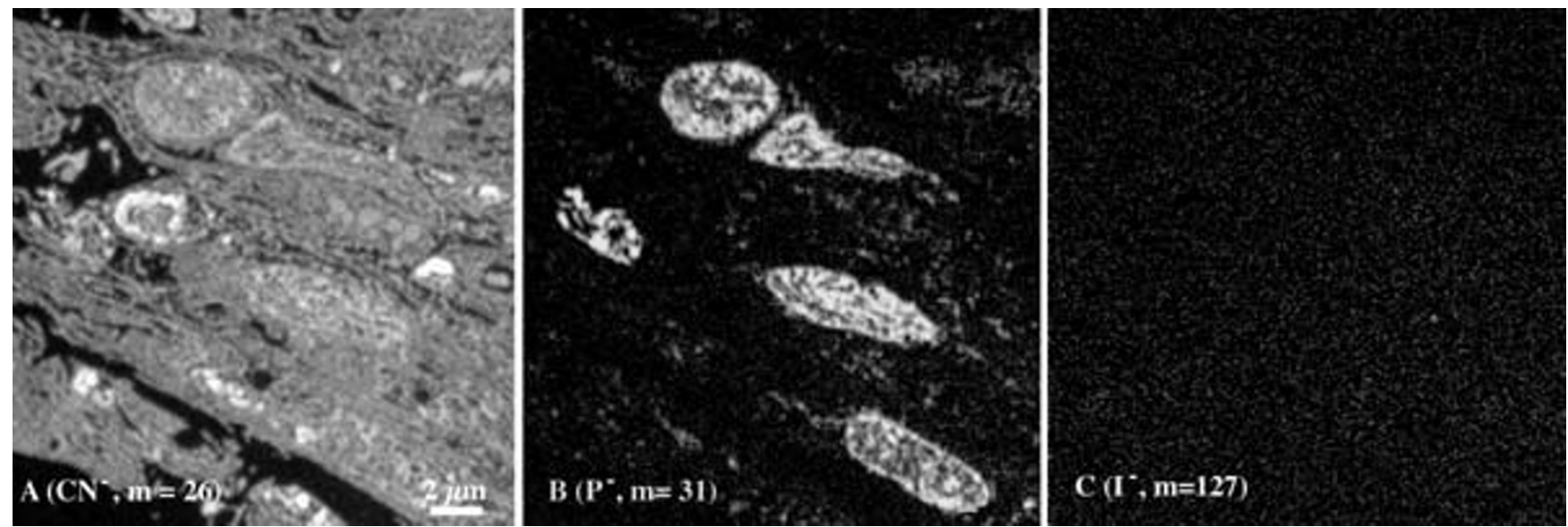

Figure 5

SIMS images of normal mouse lung tissue. $A$ : $C N$-ions $(m=26) B$ : $P$-ions $(m=3 I)-C$ : $I-$ ions $(m=I 27)$, field $20 \times 20$ $\mu \mathrm{m}$. The iodine image does not show any significant signal. 


\section{Authors' contributions}

JLGK carried out both sample preparation and image acquisition, FH setup the instrument and adjusted the microprobe; PL and JP carried out all animal experimentation; JCM and AC participated in the design and coordination of the study. All authors read and approved the final manuscript.

\section{Acknowledgements}

The NanoSims 50 was purchased with financial support from INSERM, the Research division of the Curie Institute, the "Ile de France" district, the EDF radioprotection agency and ARC (contract $n^{\circ} 740$ ). All these institutions are gratefully acknowledged. Thanks to Alvin Wald and Jason Martin for editorial assistance.

\section{References}

I. Castaing R, Slodzian G: Microanalyse par émission ionique secondaire. J Microsc 1962, I:395-4I0.

2. Galle P: Sur une nouvelle méthode d'analyse cellulaire utilisant le phénomène d'émission ionique secondaire. Ann Phys Biol Med 1970, 42:83-94.

3. Morrison GH, Gay I, Chandra S: Ion microscopy in biology. Scanning Microsc Suppl 1994, 8:359-70.

4. Pacholski ML, Winograd N: Imaging with mass spectrometry. Chem Rev 1999, 99:2977-3005.

5. Todd PJ, Schaaff TG, Chaurand P, Caprioli RM: Organic ion imaging of biological tissue with secondary ion mass spectrometry and matrix-assisted laser desorption/ionization. J Mass Spectrom 200I, 36:355-69.

6. Slodzian G, Daigne B, Girard F, Boust F, Hillion F: Scanning secondary ion analytical microscopy with parallel detection. Biol Cell 1992, 74:43-50.

7. Hillion F, Daigne B, Girard F, Slodzian G, Schuhmacher M: A new high performance SIMS instrument: The Cameca "Nanosims 50". Secondary Ion Mass Spectrometry SIMS IX 1993:254-257.

8. Weinstock MA: Epidemiology of melanoma. Cancer Treat Res 1993, 65:29-56.

9. Garbe C, Blum A: Epidemiology of cutaneous melanoma in Germany and worldwide. Skin Pharmacol Appl Skin Physiol 200I, I 4:280-90.

10. Prichard RS, Hill AD, Skehan SJ, O'Higgins NJ: Positron emission tomography for staging and management of malignant melanoma. Br J Surg 2002, 89:389-96.

II. Michelot JM, Moreau MF, Labarre PG, Madelmont JC, Veyre AJ, Papon JM, Parry DF, Bonafous JF, Boire JY, Desplanches GG: Synthesis and evaluation of new iodine- $I 25$ radiopharmaceuticals as potential tracers for malignant melanoma. J Nucl Med 199I, 32:1573-80.

12. John CS, Saga T, Kinuya S, Le N, Jeong JM, Paik CH, Reba RC, Varma VM, McAfee JG: An improved synthesis of [125I]N-(diethylaminoethyl)-4-iodobenzamide: a potential ligand for imaging malignant melanoma. Nucl Med Biol 1993, 20:75-9.

13. Labarre P, Papon J, Moreau MF, Moins N, Veyre A, Madelmont JC: Evaluation in mice of some iodinated melanoma imaging agents using cryosectioning and multi-wire proportional counting. Eur J Nucl Med 1999, 26:494-8.

14. Moins N, Papon J, Seguin H, Gardette D, Moreau MF, Labarre P, Bayle M, Michelot J, Gramain JC, Madelmont JC, Veyre A: Synthesis, characterization and comparative biodistribution study of a new series of p-iodine- 125 benzamides as potential melanoma imaging agents. Nucl Med Biol 200I, 28:799-808.

15. Labarre P, Papon J, Moreau MF, Moins N, Bayle M, Veyre A, Madelmont JC: Melanin affinity of $\mathbf{N}$-(2-diethylaminoethyl)-4-iodobenzamide, an effective melanoma imaging agent. Melanoma Res 2002, I2:|| |5-2|.

16. Moins N, D'Incan M, Bonafous J, Bacin F, Labarre P, Moreau MF, Mestas D, Noirault E, Chossat F, Berthommier E, Papon J, Bayle M, Souteyrand P, Madelmont JC, Veyre A: I 23I-N-(2-diethylaminoethyl)-2-iodobenzamide: a potential imaging agent for cuta- neous melanoma staging. Eur ] Nucl Med Mol Imaging 2002 , 29:1478-84.

17. Chehade F, De Labriolle-Vaylet C, Michelot J, Moins N, Moreau MF, Hindie E, Papon J, Escaig F, Galle P, Veyre A: Distribution of I-BZA (N-2-diethylaminoethyl-4-iodobenzamide) in grafted melanoma and normal skin: a study by secondary ion mass spectroscopy. Cell Mol Biol (Noisy-le-grand) 200I, 47:529-34.

18. John CS, Bowen WD, Saga T, Kinuya S, Vilner BJ, Baumgold J, Paik CH, Reba RC, Neumann RD, Varma VM: A malignant melanoma imaging agent: synthesis, characterization, in vitro binding and biodistribution of iodine-125-(2-piperidinylaminoethyl)4-iodobenzamide. I Nucl Med I 993, 34:2 I69-75.

19. Caveliers V, Everaert H, Lahoutte T, Dierickx LO, John CS, Bossuyt A: Labelled sigma receptor ligands: can their role in neurology and oncology be extended? Eur J Nucl Med 200I, 28: I33-5.
Publish with Bio Med Central and every scientist can read your work free of charge

"BioMed Central will be the most significant development for disseminating the results of biomedical research in our lifetime. "

Sir Paul Nurse, Cancer Research UK

Your research papers will be:

- available free of charge to the entire biomedical community

- peer reviewed and published immediately upon acceptance

- cited in PubMed and archived on PubMed Central

- yours - you keep the copyright 